\title{
Escaping the correction for body surface area when calculating glomerular filtration rate in children
}

\author{
Amy Piepsz • Marianne Tondeur • Hamphrey Ham
}

Published online: 30 November 2008

(C) Springer-Verlag 2008

Erratum to: Eur J Nucl Med Mol Imaging (2008) 35:1669-1672

DOI 10.1007/s00259-008-0820-3

On page 1670, owing to an unfortunate mix-up, an erroneous figure was published as Fig. 1. The correct figure is presented below. The authors apologize for this mistake and any confusion it may have caused.

The online version of the original can be found at http://dx.doi.org/ 10.1007/s00259-008-0820-3.

\footnotetext{
A. Piepsz $(\bowtie) \cdot$ M. Tondeur Department of Radioisotopes, CHU St Pierre,

Brussels, Belgium

e-mail: amypiepsz@yahoo.com

H. Ham

Department of Nuclear Medicine, University Hospital Ghent,

Ghent, Belgium 
Fig. 1 The 10th, 25th, 50th and 90th percentile curves of normal Cr-EDTA clearance values, not corrected for body surface, in function of age. 1a: 0.1-2 years 1b: $2-15$ years

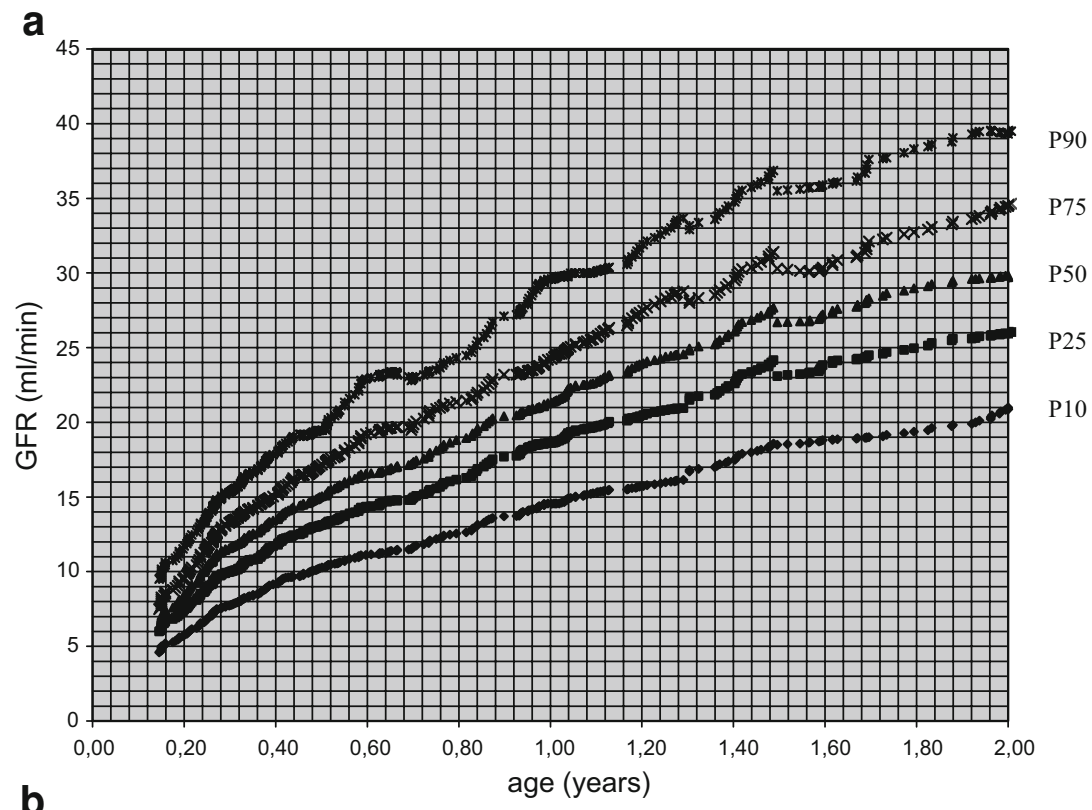

b

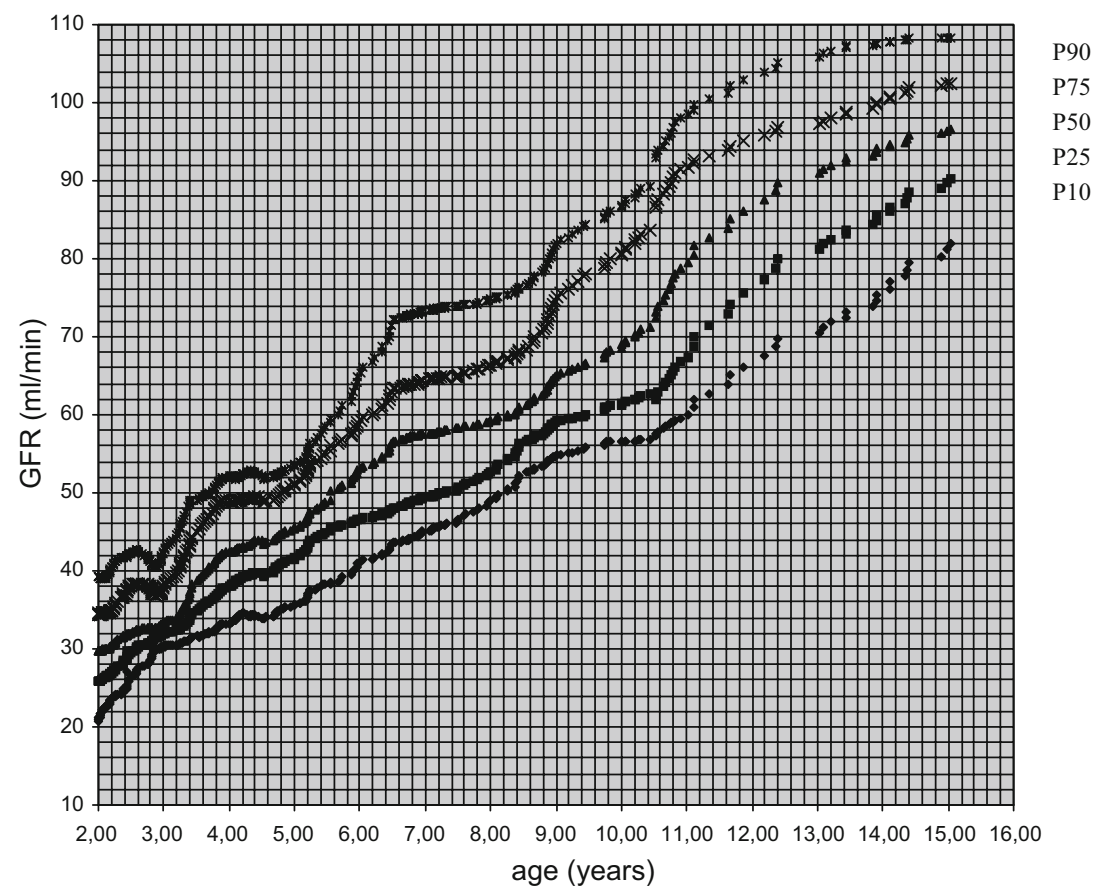

